\title{
Treatment of terminal syringomyelia in association with tethered cord syndrome: clinical outcomes with and without syrinx drainage
}

\author{
KaAn Erkan, M.D., Faruk Unal, M.D., Talat Kiris, M.D., and Turan Karalar, M.D. \\ Department of Neurosurgery, Istanbul Faculty of Medicine, Istanbul University, Istanbul,Turkey
}

\begin{abstract}
Object. Current use of magnetic resonance (MR) imaging has led to increased awareness of the frequency of terminal syringomyelia in patients with tethered cord syndrome. However, that the surgical treatment of terminal syringomyelia is necessary remains unclear.

In this study the authors attempted to assess the clinical impact, if any, brought after syrinx decompression on the clinical outcome of tethered cord syndrome.

Methods. They randomly assigned 30 cases of pediatric tethered cord into two treatment groups: those in whom an untethering procedure was performed (Group I) and those in whom this procedure was combined with syrinx decompression (Group II). The 1-year follow-up clinical results obtained in the two groups, in correlation with MR imaging findings, were compared to evaluate the benefit of added syrinx drainage.

Clinical follow-up evaluation revealed that surgical drainage of the syrinx, when combined with spinal cord untethering, resulted in better outcomes in terms of resolution of sensory deficits $(\mathrm{p}=0.036)$ and bladder dysfunction $(\mathrm{p}=$ 0.05). The improvement in clinical outcome correlated with the radiologically documented resolution of the syrinx cavity; however, response rates of symptoms differed for each tethering subgroup.

Conclusions. Preliminary results of this study indicated that terminal syringomyelia should be considered as a comorbidity that contributes to the clinical outcome of patients with tethered cord syndrome. A better clinical outcome is achieved following successful decompression of the syrinx in addition to untethering the spinal cord. These findings emphasize the importance of recognizing, evaluating, and treating this pathological entity.
\end{abstract}

\section{KEY WORDS • syringomyelia • tethered cord syndrome • terminal ventriculostomy • myelotomy}

With the advent of MR imaging terminal syringomyelia, the segmental intramedullary cystic cavitation of the caudal third of the spinal cord, ${ }^{19}$ became quite a common radiological finding in association with congenital spinal cord anomalies..$^{5,20,37,42}$ In recent studies the authors have described the overall clinical and radiological features of this pathological entity, documenting a prevalence of 22.5 to $53 \%$, associated most often with tethered spinal cord. ${ }^{6,8,19,30}$ However, little is known regarding the causal factors leading to the syrinx formation or the contribution of this added entity to the overall clinical picture. Furthermore, although a number of authors ${ }^{6,24,45}$ have described the beneficial effect of performing syrinx drainage on the clinical outcome in patients with tethered cord syndrome, it is not clear whether surgical treatment of the syrinx is necessary, because the authors of these studies did not prospectively compare their results with a concurrent control group.

In this study we endeavor to assess the clinical impact, if any, of syrinx decompression on the surgical outcome. We performed a prospective evaluation of the clinical and

Abbreviations used in this paper: $\mathrm{CI}=$ confidence interval; $\mathrm{CSF}=$ cerebrospinal fluid; $\mathrm{MR}=$ magnetic resonance. radiological outcomes of patients who underwent an untethering procedure, with or without syrinx drainage. The 1-year follow-up clinical results obtained in these two groups, in association with the MR imaging-documented findings, were evaluated to determine the benefit of added syrinx drainage.

\section{CLINICAL MATERIAL AND METHODS}

\section{Patient Population}

Between March 1992 and February 1998, 30 pediatric patients presenting to our department with terminal syringomyelia in association with tethered cord syndrome were enrolled in this study. The indications for inclusion in this series were the progressive deterioration of neurological deficits, radiological evidence of distal syringomyelia confined within the caudal third of the spinal cord, and no radiological evidence of any craniocervical anomaly, hindbrain deformity, or hydrocephalus. Patients with complete paraplegia were not included. Of the 30 patients, 19 were girls and 11 were boys, ranging in age from 12 months to 16 years $(6.2 \pm 4.4$ years [mean \pm standard deviation]); $56.6 \%$ of the patients were between the ages 
of 3 and 9 years. Spinal cord tethering was caused by thick filum terminale (40\%), diastematomyelia (43.3\%), repaired lipomyelomeningocele site $(13.3 \%)$, and diastematomyelia associated with terminal lipoma (3.3\%). Presenting symptoms included, alone or in various combinations, progressive lower-extremity weakness $(76.6 \%)$, gait deterioration $(43.3 \%)$, sensory deficits $(86.6 \%)$, lowback or leg pain $(33.3 \%)$, urinary incontinence $(70 \%)$, bowel dysfunction (36.6\%), and/or progressive kyphoscoliosis $(50 \%)$, complicated with congenital vertebral anomalies $(70 \%)$ such as hemivertebrae $(67 \%)$, block vertebrae $(13 \%)$, or unsegmented bar $(20 \%)$. The symptoms had been present for 6 months to 3 years $(1.5 \pm 0.7$ years [mean \pm standard deviation]) with steady progression in all patients.

\section{Diagnostic Workup}

All patients underwent MR imaging of the entire spinal cord and brain as part of our standard protocol. The imaging was performed using a 1.5 tesla General Electric Signa scanning unit (General Electric, Milwaukee, WI). Both $\mathrm{T}_{1}$-weighted (TR 600-800 msec; TE 20-25 msec; number of excitations 2-4;256 $\times 256$ matrix) and $\mathrm{T}_{2}$-weighted (TR 2000-3000 msec; TE 80-100 msec; number of excitations 2; $256 \times 256$ matrix) MR sequences were obtained, with consecutive sagittal, axial, and coronal views. To assess the morphological features and the anatomical relationship of each syrinx, consecutive axial MR images were obtained in 3 to 5-mm thin sections through the area of cavitation. The selected parameters to define the morphology syrinx includeNature 403(6768):383-384, 2000d length (in vertebral segments), maximum transverse and sagittal cavity diameters (in millimeters), crosssectional location, intensity, and syrinx index (cross-sectional syringeal area assessed as a percentage of the spinal cord area, at the level of the widest cyst dimension, as determined on axial images). ${ }^{12}$ All measurements were made from the hard-copy images by using calipers and the relative MR imaging scale generated on each image. Additional information was obtained in all patients by conducting computerized tomography, plain radiography of the head and spine, and urodynamic (cystometrography, uroflowmetry, and pelvic electromyography) studies.

\section{Surgical Treatment}

The patients were randomly assigned to undergo one of the two standard procedures: 1) standard untethering of the spinal cord (Group I; or 2) untethering of the spinal cord combined with an additional surgical approach to decompress the syrinx (Group II). Accordingly, in 16 children only spinal cord untethering was performed, whereas in 14 children spinal cord release was followed by either terminal ventriculostomy (in eight patients) or dorsal midline myelotomy (in six).

The untethering procedure was performed by dividing the thickened, fatty filum terminale through a limited laminectomy and, when necessary, by excision of any lesion (bony spur, terminal lipoma) and dissection of any arachnoidal adhesions to reconstitute a patent and capacious thecal sac, which allowed the conus medullaris to move freely. The type of drainage procedure depended mainly on the radiologically demonstrated morphological fea- tures of the syrinx; a classical terminal ventriculostomy was considered when the low-lying syrinx extended to the conus medullaris, whereas simple drainage, via dorsal midline myelotomy, was preferred in cases in which there were segmental unilocular thoracic cavities, at the level of maximal cyst dilation.

\section{POSTOPERATIVE EVALUATION}

According to the protocol, the patients underwent follow-up examination at 6 weeks, 6 months, and 1 year postoperatively and thereafter at 1-year intervals in the neurosurgery, pediatric neurology, and pediatric urology clinics. Postoperative responses with respect to motor strength, sensory deficits, and urinary incontinence were classified as worse, unchanged, or improved on the basis of the quantitative grading system presented by Klekamp and Samii. ${ }^{23}$ The classification of "improved" was used to describe a minimum improvement of one grade in each category, and the term "worse" was attributed to further progression of the symptom.

Control MR images were obtained in all patients at 6 and 12 months postsurgery and once a year thereafter. A decrease in the syrinx index of $50 \%$ or more, as revealed on MR studies, was considered evidence that syrinx size was reduced. In patients with bladder dysfunction, urodynamic studies were repeated postoperatively at 1 year to record any objective improvement.

\section{Statistical Analysis}

We compared the surgical neurological outcomes between the two treatment modalities. The chi-square test or the Fischer's exact test was used to compare the "improvement" proportions of the selected baseline clinical (motor, sensory, and bladder), and radiological (syrinx index) data obtained at 1-year follow up. Point estimates and 95\% CI were calculated to assess the magnitude and importance of this difference in terms of clinical significance. Two-tailed tests of significance were used with a nominal probability value of 0.05 .

\section{RESULTS}

Characteristics such as age, causes of tethering, vertebral level of tethering were similar between the two treatment groups (Table 1). Despite the higher prevalence of paresis and congenital scoliosis in the group of patients who underwent an untethering-alone procedure (Group I) or of the bladder and bowel dysfunction in the patients who underwent untethering/drainage (Group II), the differences in presenting symptoms were not statistically significant. Likewise, the minimally observed differences in the mean duration of symptoms, the magnitude of the baseline neurological scores of motor function, sensory deficits, and bladder function, and the morphological characteristics of the syrinx cavities were insignificant (Table 1).

\section{Clinical Outcome}

Clinical outcomes in the 16 Group I patients (Table 2) and in the 14 Group II patients (Table 2) were evaluated at 1 -year follow-up examination. In general, in patients in 
TABLE 1

Clinical and radiological data obtained in 30 patients with terminal syringomyelia

\begin{tabular}{|c|c|c|}
\hline Variable & $\begin{array}{l}\text { Group I } \\
\text { (16 cases) }\end{array}$ & $\begin{array}{l}\text { Group II } \\
\text { (14 cases) }\end{array}$ \\
\hline \multirow{2}{*}{\multicolumn{3}{|c|}{$\begin{array}{c}\text { clinical data } \\
\text { age }\end{array}$}} \\
\hline & & \\
\hline range & $1-13$ yrs & $1-16 \mathrm{yrs}$ \\
\hline mean $\pm \mathrm{SD}$ & $6.1 \pm 4.2 \mathrm{yrs}$ & $6.3 \pm 4.8 \mathrm{yrs}$ \\
\hline \multicolumn{3}{|l|}{ tethering causes } \\
\hline thick filum & $6(38 \%)$ & $6(43 \%)$ \\
\hline diastematomyelia & $8(50 \%)$ & $6(43 \%)$ \\
\hline previous op* & $2(12 \%)$ & $2(14 \%)$ \\
\hline \multicolumn{3}{|l|}{ clinical presentation } \\
\hline motor deficits & $14(88 \%)$ & $9(64 \%)$ \\
\hline sensory deficits & $14(88 \%)$ & $12(86 \%)$ \\
\hline bladder dysfunction & $10(68 \%)$ & $11(79 \%)$ \\
\hline bowel dysfunction & $5(31 \%)$ & $5(36 \%)$ \\
\hline scoliosis & $10(63 \%)$ & $5(36 \%)$ \\
\hline \multicolumn{3}{|l|}{ duration of symptoms (mos) } \\
\hline mean & $18 \pm 9.6$ & $19 \pm 10.8$ \\
\hline range & $6-36$ & $6-36$ \\
\hline \multicolumn{3}{|l|}{ radiological data } \\
\hline \multicolumn{3}{|l|}{ cross-sectional location } \\
\hline central & $4(25 \%)$ & $4(29 \%)$ \\
\hline paracentral & $11(75 \%)$ & $10(71 \%)$ \\
\hline \multicolumn{3}{|l|}{ syrinx length } \\
\hline (in vertebral segments) $\dagger$ & $4.2 \pm 1.7$ & $4.3 \pm 1.6$ \\
\hline \multicolumn{3}{|l|}{ syrinx diameter (in $\mathrm{mm}) \div$} \\
\hline transverse & $3.0 \pm 1.7$ & $3.0 \pm 1.4$ \\
\hline sagittal & $13.3 \pm 1.8$ & $4.0 \pm 1.2$ \\
\hline syrinx index & $0.40 \pm 0.20$ & $0.45 \pm 0.16$ \\
\hline
\end{tabular}

* Spinal cord tethering due to previous surgery for lipomyelomeningocele. $\dagger$ Values are presented as the mean \pm standard deviation.

Group II better clinical outcomes were demonstrated than in those in Group I patients in whom untethering alone was performed (78\% compared with $45 \%$, respectively; $\mathrm{p}=0.05$ ); however, amelioration of motor, sensory, and urinary symptoms differed.

Motor Outcome. Of the nine patients with paresis in Group II, seven (78\%) improved, one (11\%) worsened, and one $(11 \%)$ was unchanged, whereas of the 14 patients in Group I with paresis, improvement was attained in seven $(50 \%)$, deterioration continued in one $(7 \%)$, and no change was observed in six patients $(43 \%)$.

Sensory Outcome. Of the 12 patients with sensory deficits in Group II, 11 (92\%) improved, and one (8\%) was unchanged, whereas of the 14 patients in Group I, improvement was observed in seven $(50 \%)$ and no change or worsened in seven (50\%).

Urinary Outcome. Of the 11 patients with incontinence in Group II, eight (70\%) improved and three (27\%) were unchanged, whereas of the 10 patients with incontinence in Group I, improvement was seen in three (30\%) and no change was observed in seven (70\%).

The differences in the improvement rates of sensory deficits and urinary dysfunction between two treatment groups were statistically significant $(\mathrm{p}=0.036$ and $\mathrm{p}=$ 0.05 , respectively) and were large enough to be of clinical importance (95\% CI 10-70 and 95\% CI 12-68, respectively), in favor of the patients in Group II who underwent the combined procedure. Results of motor improvement did not reach statistical significance when the two groups were compared ( $\mathrm{p}=0.228,95 \% \mathrm{CI}-9$ to 66$)$.

\section{Radiological Outcome}

Control MR images obtained 1 year postoperatively demonstrated a reduction in syrinx size in 15 cases $(50 \%)$, no change in 14 cases $(47 \%)$, and enlargement in one case $(3 \%)$. To evaluate the correlation between radiological and neurological outcomes, clinical responses in motor, sensory, and urinary symptoms were compared between the syrinx size-reduced and syrinx size-unchanged cases. Compared with the improvement in six of 12 cases with unchanged syrinx size, resolution of the sensory deficits was observed in 12 of 14 in whom syrinx size was reduced ( $p=0.046$, 95\% CI 2-68). Likewise, improvement in bladder dysfunction seen in three of nine patients in whom syrinx size was unchanged, was observed in 10 of 12 patients in whom syrinx size was reduced $(\mathrm{p}=0.019,95 \%$ CI 10-90). However, the motor improvement rate between patients in whom the syrinx size was unchanged (five of 11) and those in whom it was reduced (nine of 12) was not significant ( $\mathrm{p}=0.214,95 \% \mathrm{CI}-5$ to 69$)$.

\section{Subgroup Analysis}

Because the response to surgery varies in each form of spinal dysraphism as a consequence of the morbid anatomy of the myelodysplastic spinal cord, clinical outcomes in syrinx-unchanged and syrinx-reduced cases were compared within the homogenous tethering subgroups. In thick filum terminale cases, improvement was attained in five of the five cases with reduced syrinx size, as compared with two of the seven cases with unchanged syrinx size $(p=0.028)$. Of interest, four of the five cases with unchanged clinical outcome, had distended syrinx cavities with syrinx index of more than or equal to $50 \%$. In patients with diastematomyelia in whom the syrinx was reduced in size, a $100 \%$ improvement rate was demonstrated (six of six), whereas this rate was $50 \%$ (four of eight) in those with unchanged syrinx size $(p=0.085)$. In previously operated lipomyelomeningocele cases, only one of the four patients with reduced syrinx size improved, and no improvement was noted in the patient with unchanged syrinx size $(\mathrm{p}=1.00)$.

There was no surgery-related mortality; however, additional neurological deficits were observed after myelotomy procedures in which small syringes (syrinx index $<$ $40 \%)$ were treated: two patients experienced transient dysesthesia (in a dermatome corresponding to the location of their myelotomy); one patient defined saddle numbness; and in one patient bladder distention occurred. The latter patient regained bladder control within 6 weeks, and dysesthesia resolved in former cases by 4 to 6 months.

\section{DISCUSSION}

Current use of MR imaging has led to increased recognition of terminal syringomyelia, which is found alone $\mathrm{e}^{30,39}$ or in association with diverse forms of spinal dysraphism., $3,14,17,41$ Recently, the authors of large studies have described the clinical and radiological characteristics of this pathological entity, reporting a prevalence of 22.5 to $53 \%$, most often associated with tethered spinal cord. ${ }^{2,5,13,19} \mathrm{Ne}$ - 
K. Erkan, et al.

TABLE 2

Magnetic resonance imaging data and outcome in Group I and II patients

\begin{tabular}{|c|c|c|c|c|c|c|c|c|c|c|c|}
\hline \multirow{3}{*}{$\begin{array}{l}\text { Case } \\
\text { No. } \\
\end{array}$} & \multicolumn{4}{|c|}{ Preop } & \multicolumn{4}{|c|}{ Postop } & & & \\
\hline & \multirow{2}{*}{$\begin{array}{c}\text { Syrinx } \\
\text { Span }\end{array}$} & \multirow{2}{*}{$\begin{array}{l}\text { Widest } \\
\text { Diameter } \\
(\mathrm{mm})\end{array}$} & \multirow{2}{*}{$\begin{array}{c}\text { Syrinx } \\
\text { Index } \\
(\%)\end{array}$} & \multirow[b]{2}{*}{ Surgery } & \multirow{2}{*}{$\begin{array}{c}\text { Syrinx } \\
\text { Span }\end{array}$} & \multirow{2}{*}{$\begin{array}{c}\text { Widest } \\
\text { Diameter } \\
(\mathrm{mm})\end{array}$} & \multirow{2}{*}{$\begin{array}{c}\text { Syrinx } \\
\text { Index } \\
(\%)\end{array}$} & \multirow[b]{2}{*}{ RO } & \multicolumn{3}{|c|}{ Outcome } \\
\hline & & & & & & & & & Motor & Sensory & Urinary \\
\hline \multicolumn{12}{|c|}{ Group I } \\
\hline 1 & Т8-9 & $1 \times 2$ & 0.2 & $\mathrm{U}$ & T8-9 & $1 \times 2$ & 0.2 & $\mathrm{~S}$ & improved & improved & \\
\hline 2 & L1-5 & $3 \times 4$ & 0.5 & U & L1-5 & $3 \times 4$ & 0.5 & $\mathrm{~S}$ & unchanged & unchanged & unchanged \\
\hline 3 & T7-8 & $1 \times 2$ & 0.15 & $\mathrm{U}$ & T7-8 & $1 \times 2$ & 0.15 & $\mathrm{~S}$ & improved & improved & \\
\hline 4 & T8-10 & $2 \times 3$ & 0.3 & $\mathrm{U}$ & T8-10 & $2 \times 3$ & 0.3 & $\mathrm{~S}$ & unchanged & unchanged & \\
\hline 5 & T11-L3 & $5 \times 5$ & 0.5 & $\mathrm{U}$ & T11-L3 & $2 \times 3$ & 0.2 & $\mathrm{R}$ & worsened & unchanged & unchanged \\
\hline 6 & T8-12 & $6 \times 5$ & 0.55 & $\mathrm{U}$ & T8-11 & $5 \times 5$ & 0.45 & $\mathrm{~S}$ & unchanged & unchanged & unchanged \\
\hline 7 & T8-L1 & $5 \times 7$ & 0.5 & $\mathrm{U}$ & $\mathrm{T} 11-\mathrm{L} 1$ & $2 \times 4$ & 0.2 & $\mathrm{R}$ & improved & improved & improved \\
\hline 8 & T8-12 & $2 \times 2$ & 0.3 & $\mathrm{U}$ & T8-12 & $2 \times 2$ & 0.3 & $\mathrm{~S}$ & improved & improved & \\
\hline 9 & T12-L4 & $6 \times 5$ & 0.75 & $\mathrm{U}$ & T12-L4 & $4 \times 4$ & 0.5 & $S$ & unchanged & unchanged & unchanged \\
\hline 10 & L2-3 & $2 \times 2$ & 0.35 & $\mathrm{U}$ & L2-3 & $2 \times 2$ & 0.35 & $\mathrm{~S}$ & improved & improved & \\
\hline 11 & T7-12 & $4 \times 5$ & 0.5 & $\mathrm{U}$ & $\mathrm{T} 7-12$ & $4 \times 5$ & 0.5 & $\mathrm{~S}$ & unchanged & unchanged & unchanged \\
\hline 12 & T11-L4 & $2 \times 3$ & 0.35 & $\mathrm{U}$ & T11-L4 & $2 \times 3$ & 0.35 & $\mathrm{~S}$ & unchanged & unchanged & \\
\hline 13 & L1-5 & $3 \times 3$ & 0.5 & $\mathrm{U}$ & L1-3 & $1 \times 1$ & 0.15 & $\mathrm{R}$ & improved & improved & improved \\
\hline 14 & T10-L3 & $2 \times 2$ & 0.35 & $\mathrm{U}$ & L1-3 & $1 \times 1$ & 0.15 & $\mathrm{R}$ & improved & improved & improved \\
\hline 15 & L2-3 & $1 \times 1$ & 0.15 & $\mathrm{U}$ & L2-3 & $2 \times 3$ & 0.35 & I & & & unchanged \\
\hline 16 & $\mathrm{~L} 2-3$ & $2 \times 3$ & 0.45 & $\mathrm{U}$ & L2-3 & $2 \times 3$ & 0.45 & S & & & unchanged \\
\hline \multicolumn{12}{|c|}{ Group II } \\
\hline 17 & L3-5 & $1 \times 2$ & 0.2 & $\mathrm{U}+\mathrm{Tv}$ & L3-4 & $1 \times 2$ & 0.2 & $\mathrm{~S}$ & improved & improved & unchanged \\
\hline 18 & T8-10 & $3 \times 4$ & 0.4 & $\mathrm{U}+\mathrm{M}$ & T8-9 & $1 \times 2$ & 0.15 & $\mathrm{R}$ & & improved & improved \\
\hline 19 & $\mathrm{~L} 1-\mathrm{S} 1$ & $2 \times 3$ & 0.35 & $\mathrm{U}+\mathrm{TV}$ & L1-5 & $1 \times 1$ & 0.15 & $\mathrm{R}$ & improved & improved & improved \\
\hline 20 & T7-11 & $6 \times 5$ & 0.7 & $\mathrm{U}+\mathrm{M}$ & T7-8 & $2 \times 3$ & 0.25 & $\mathrm{R}$ & worsened & unchanged & unchanged \\
\hline 21 & T8-12 & $4 \times 5$ & 0.55 & $\mathrm{U}+\mathrm{M}$ & T8-10 & $2 \times 2$ & 0.2 & $\mathrm{R}$ & improved & improved & \\
\hline 22 & T11-L3 & $2 \times 2$ & 0.2 & $\mathrm{U}+\mathrm{Tv}$ & T11-L1 & $2 \times 2$ & 0.2 & $\mathrm{~S}$ & & improved & improved \\
\hline 23 & L2-5 & $3 \times 5$ & 0.5 & $\mathrm{U}+\mathrm{Tv}$ & L2-4 & $1 \times 2$ & 0.15 & $\mathrm{R}$ & & improved & improved \\
\hline 24 & T8-10 & $4 \times 4$ & 0.4 & $\mathrm{U}+\mathrm{M}$ & & & 0 & $\mathrm{R}$ & improved & improved & \\
\hline 25 & T11-L2 & $3 \times 5$ & 0.5 & $\mathrm{U}+\mathrm{Tv}$ & T12-L1 & $1 \times 2$ & 0.15 & $\mathrm{R}$ & improved & improved & improved \\
\hline 26 & T12-L2 & $3 \times 4$ & 0.5 & $\mathrm{U}+\mathrm{M}$ & T12-L1 & $1 \times 2$ & 0.2 & $\mathrm{R}$ & improved & improved & \\
\hline 27 & T8-L3 & $5 \times 5$ & 0.65 & $\mathrm{U}+\mathrm{M}$ & T8-L2 & $2 \times 2$ & 0.25 & $\mathrm{R}$ & unchanged & improved & improved \\
\hline 28 & T11-L4 & $3 \times 4$ & 0.4 & $\mathrm{U}+\mathrm{TV}$ & T10-L2 & $1 \times 1$ & 0.1 & $\mathrm{R}$ & improved & improved & improved \\
\hline 29 & L1-2 & $1 \times 2$ & 0.2 & $\mathrm{U}+\mathrm{Tv}$ & & & 0 & $\mathrm{R}$ & & & improved \\
\hline 30 & L3-5 & $3 \times 4$ & 0.45 & $\mathrm{U}+\mathrm{TV}$ & L3-4 & $3 \times 4$ & 0.45 & $\mathrm{~S}$ & & & unchanged \\
\hline
\end{tabular}

* $\mathrm{I}=$ increased syrinx size; $\mathrm{R}=$ reduced syrin $\mathrm{x}$ size; $\mathrm{RO}=$ radiological outcome; $\mathrm{S}=$ stationary syrinx size; $\mathrm{U}=$ untethering; $\mathrm{U}+\mathrm{M}=\mathrm{untethering}$ and $\mathrm{my}-$ elotomy; $\mathrm{U}+\mathrm{Tv}=$ untethering and terminal ventriculostomy.

vertheless, the causal factors leading to terminal syringomyelia remain unclear. ${ }^{11,15,18,44}$ The consistent appearance of the syringes confined to the caudal spinal cord, usually close and rostral to an associated dysraphic lesion, has been speculated to be meaningful on a dysraphic basis. ${ }^{10,29}$ A number of embryological theories considering the terminal syrinx as the anomalous persistence of ventriculus terminalis, subsequent to defective retrogresseive differentiation have been suggested. ${ }^{27,35,39}$ However, neither the symptomatic and radiological improvement observed after syrinx drainage, ${ }^{6,19,24}$ nor the occurrence of de novo syringes following the retethering conditions, ${ }^{7,43}$ can be explained by these hypotheses. Although the persistence of a prominent ventriculus terminalis might provide an anatomical basis for the terminal syrinx, coexisting factors, such as spinal cord ischemia ${ }^{21,38}$ and altered local CSF dynamics, ${ }^{4,34}$ should be taken into consideration. Further research addressing the regional CSF dynamics, ${ }^{26}$ intrasyrinx pressures, ${ }^{31}$ and local spinal cord blood flow ${ }^{33}$ are necessary to elucidate the pathophysiology of terminal syringomyelia.

Controversy exits regarding the necessity for treatment of terminal syringomyelia in cases of tethered spinal cord.
On the basis of the results of recent clinical studies, syrinx decompression has been proposed as a beneficial supplementary procedure. . $^{6,19,24,45}$ To date, no study has been conducted to make a critical comparison of surgical outcomes in patients who underwent an untethering procedure as compared with those in whom untethering and syrinx drainage were performed. The purpose of our study was to determine the relative merits of combining the untethering procedure with syrinx drainage on the clinical outcome.

Despite the small number of patients in this study, there are two main findings. First, surgical drainage of the syrinx, when combined with a standard spinal cord untethering procedure, resulted in better clinical outcome at 1-year follow up (in terms of resolution of sensory deficits and improvement in bladder function) as compared with a simple untethering procedure alone. Second, the prognosis of neurological outcome correlated with the postoperative radiological outcome: in general, the radiological resolution of the syrinx cavity resulted in a better resolution of symptoms. However, the response to surgery varied with respect to the cause of the tethering. In cases of thick filum terminale, reduction of the syrinx cavity was accompanied by the resolution of symptoms, whereas the persis- 


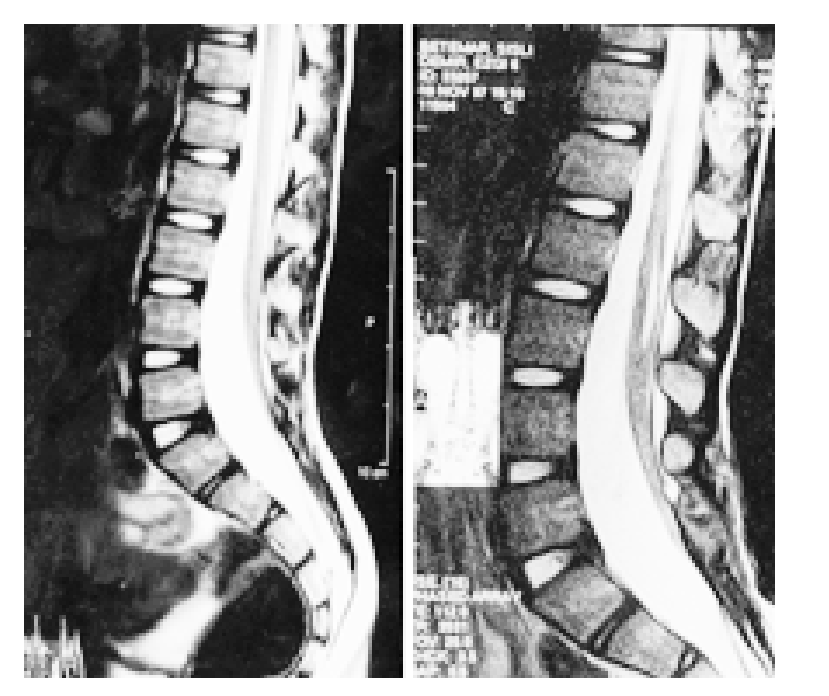

Fig. 1. Sagittal midline $\mathrm{T}_{2}$-weighted MR images demonstrating the lumbosacral cord. Left: Prior to surgery an elongated conus medullaris, with posterior tethering at L5-S1 level, and a small caudal syrinx at L2-3 level are seen. Right: Twelve months after surgery, there is marked enlargement in the syrinx cavity with posterior retethering demonstrated at S-1.

tence of distended syringes (syrinx index $\geq 50 \%$ ) resulted in "unchanged" clinical response despite the radiologically confirmed diagnosis of successful untethering. On the other hand, in cases of lipomyelomeningocele, reduction of the syrinx cavity did not reverse the progressive neurological deterioration. The variation of these congenital lesions in response to surgery, as determined by the functional anatomy of the dysmorphic spinal cord, ${ }^{46}$ was in accordance with the results obtained in previously published larger series. ${ }^{1,9,17}$

Several operative approaches to distal syringomyelia in association with occult spinal dyraphism have been described. The most common approaches are myelotomy ${ }^{45}$ terminal ventriculostomy ${ }^{6,45}$ syringosubarachnoid shunt placement,${ }^{7,19,24}$ syringoperitoneal shunt placement, ${ }^{43}$ and lumboperitoneal shunting following the drainage of the syrinx.$^{36}$ In our series, from the technical standpoint, the simplest drainage procedures such as myelotomy and terminal ventriculostomy were performed.

It was not our intention to compare different treatment modalities or to elucidate the optimum surgical option for managing terminal syringomyelia. Nevertheless, more on the basis of failures than successes, we have reached some conclusions. 1) Surgical results of terminal ventriculostomy were not encouraging; only five of eight procedures resulted in reducing syrinx size, probably due to early healing of the ventriculostomy site, as criticized by Williams. ${ }^{40}$ 2) A dorsal midline myelotomy, when performed in small syringes (syrinx index $<40 \%$ ), resulted in additional neurological morbidities, such as dysesthesia and bowel dysfunction. In view of the static radiological prognosis after untethering, small syringes should probably be left untreated, and the syrinx should be followed with serial MR imaging. 3) Inadequate dissection of subarachnoid adhesions resulted in enlargement of the syrinx cavity, in addition to symptomatic retethering (Fig. 1). The marked and sustained shrinkage of the terminal syr-

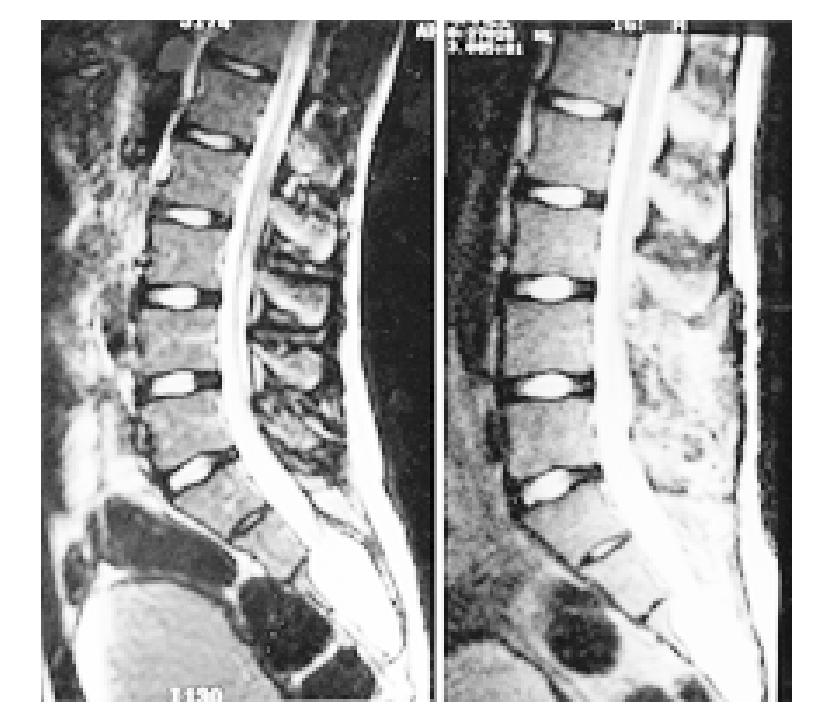

Fig. 2. Sagittal midline $\mathrm{T}_{2}$-weighted MR images demonstrating the lumbosacral cord. Left: Preoperative image revealing an ovoid terminal syrinx at L3-5 adjacent to the posteriorly tethered conus medullaris at L5-S1. Right: One-year postoperative image demonstrating shrinkage of the syrinx, within the ascended conus medullaris at L3-4, following simple untethering, as well as restoration of a patent thecal sac by lysing the arachnoidal adhesions.

inges, following the restoration of a patent and capacious thecal sac in patients in whom untethering alone was performed (Fig.2), was suggestive that arachnoiditis-induced impairment of subarachnoid CSF flow contributed to the maintenance and progression of terminal syrinx. We suggest that in all cases surgery should be directed at the establishment of a patent and capacious subarachnoid space dorsal to the conus, regardless of the primary management modality not only to minimize the risk of retethering but also with respect of the prognosis of the syrinx. The reversability of syringomyelia after restoration of CSF pathways, following posterior fossa decompression, ${ }^{16,34}$ removal of extramedullary masses, ${ }^{32}$ and expansile duraplasty with lysis of arachnoidal adhesions, ${ }^{22,25,28}$ has been documented in several recent studies.

\section{CONCLUSIONS}

Because better clinical responses are found after successful syrinx drainage combined with untethering procedure, we recommend that this pathological entity be considered as a comorbidity rather than as an incidental finding. Surgical treatment of terminal syringomyelia should be considered in conjunction with the degree of intramedullary distention, the pathological anatomy of dysplastic cord, and progression of the neurological deterioration.

In this study we have provided statistically significant clinical evidence that terminal syringomyelia affects the surgical outcome in patients with tethered cord syndrome. However, future larger prospective trials, with longer follow-up periods, are warranted to confirm our limited experience.

\section{References}

1. Andar UB, Harkness WF, et al: Split cord malformations of the lumbar region. A model for the neurosurgical management of 
all types of 'occult' spinal dysraphism? Pediatr Neurosurg 26: 17-24, 1997

2. Azimullah PC, Smit LM, Rietveld-Knol E, et al: Malformations of the spinal cord in 53 patients with spina bifida studied by magnetic resonance imaging. Childs Nerv Syst 7:63-66, 1991

3. Batnitzky S, Hall PV, Lindseth RE, et al: Meningomyelocele and syringohydromyelia. Some radiological aspects. Radiology 120:351-357, 1976

4. Batzdorf U (ed): Syringomyelia. Current Concepts in Diagnosis and Treatment. Baltimore: Williams \& Wilkins, 1991

5. Brophy JD, Sutton LN, Zimmermann RA, et al: Magnetic resonance imaging of lipomyelomeningocele and tethered cord. Neurosurgery 25:336-340, 1989

6. Caldarelli M, Di Rocco C, La Marca F: Treatment of hydromyelia in spina bifida. Surg Neurol 50:411-420, 1998

7. Chapman PH, Frim DM: Symptomatic syringomyelia following surgery to treat retethering of lipomyelomeningoceles. J Neurosurg 82:752-755, 1995

8. Coleman LT, Zimmerman RA, Rorke LB: Ventriculus terminalis of the conus medullaris: MR imaging in children. AJNR 16:1421-1426, 1995

9. Cornette L, Verpoorten C, Lagae L, et al: Tethered cord syndrome in occult spinal dysraphism: timing and outcome of surgical release. Neurology 50:1761-1765, 1998

10. Eggers C, Hamer J: Hydrosyringomyelia in childhood. Clinical aspects, pathogenesis and therapy. Neuropadiatrie 10:87-99, 1979

11. Gardner WJ: Hydrodynamic mechanism of syringomyelia: its relationship to myelocele. J Neurol Neurosurg Psychiatry 28: 247-259, 1965

12. Grant R, Hadley DM, MacPherson P, et al: Syringomyelia: cyst measurement by magnetic resonance imaging and comparison with symptoms, signs and disability. J Neurol Neurosurg Psychiatry 50:1008-1014, 1987

13. Gupta RK, Sharma A, Jena A, et al: Magnetic resonance evaluation of spinal dysraphism in children. Childs Nerv Syst 6: $161-165,1990$

14. Han JS, Benson JE, Kaufman B, et al: Demonstration of diastematomyelia and associated abnormalities with MR imaging. AJNR 6:215-219, 1985

15. Hardwidge C, Williams B: Spina bifida and syringomyelia. Childs Nerv Syst 8:173, 1992 (Abstract)

16. Heiss JD, Patronas N, DeVroom HL, et al: Elucidating the pathophysiology of syringomyelia. J Neurosurg 91:553-562, 1999

17. Herman JM, McLone DG, Storrs BB, et al: Analysis of 153 patients with myelomeningocele or spinal lipoma reoperated upon for a tethered cord. Presentation management and outcome. Pediatr Neurosurg 19:243-249, 1993

18. Hoffman HJ, Hendrick EB, Humphreys RP: The tethered spinal cord: its protean manifestations, diagnosis and surgical correction. Childs Brain 2:145-155, 1976

19. Iskandar BJ, Oakes WJ, McLaughlin C, et al: Terminal syringohydromyelia and occult spinal dysraphism. J Neurosurg 81: 513-519, 1994

20. Jaspan T, Worthington BS, Holland IM: A comparative study of magnetic resonance imaging and computed tomography-assisted myelography in spinal dysraphism. Br J Radiol 61: 445-453, 1988

21. Kang JK, Kim MC, Kim DS, et al: Effects of tethering on regional spinal cord blood flow and sensory-evoked potentials in growing cats. Childs Nerv Syst 3:35-39, 1987

22. Klekamp J, Batzdorf U, Samii M, et al: Treatment of syringomyelia associated with arachnoid scarring caused by arachnoiditis or trauma. J Neurosurg 86:233-240, 1997

23. Klekamp J, Samii M: Introduction of a score system for the clinical evaluation of patients with spinal processes. Acta Neurochir 123:221-223, 1993

24. Koyanagi I, Iwasaki Y, Hida K, et al: Surgical treatment of syringomyelia associated with spinal dysraphism. Childs Nerv Syst 13:194-200, 1997
25. Levi AD, Sonntag VK: Management of posttraumatic syringomyelia using an expansile duraplasty. A case report. Spine 23: 128-132, 1998

26. Levy LM: MR imaging of cerebrospinal fluid flow and spinal cord motion in neurological disorders of the spine. Magn Reson Imaging Clin N Am 7:573-587

27. Li L, Li Z, Wang LY, et al: Anorectal anomaly: neuropathological changes in the sacral spinal cord. J Pediatr Surg 28: 880-885, 1993

28. Mallucci CL, Stacey RJ, Miles JB, et al: Idiopathic syringomyelia and the importance of occult arachnoid webs, pouches and cysts. Br J Neurosurg 11:306-309, 1997

29. McGrath JT: Spinal dysraphism in the dog with comments on syringomyelia. Pathol Vet 2:1-45, 1965

30. Meltzer H, James HE, Trauner D, et al: Syringomyelia of the distal spinal cord in children. Pediatr Neurosurg 22:248-250, 1995

31. Milhorat TH, Capocelli AL Jr, Kotzen RM, et al: Intramedullary pressure in syringomyelia: clinical and pathophysiological correlates of syrinx distention. Neurosurgery 41:1102-1110, 1997

32. Milhorat TH, Johnson RW, Milhorat RH, et al: Clinicopathological correlations in syringomyelia using axial magnetic resonance imaging. Neurosurgery 37:206-213, 1995

33. Milhorat TH, Kotzen RM, Capocelli AL Jr, et al: Intraoperative improvement of somatosensory evoked potentials and local spinal cord blood flow in patients with syringomyelia. J Neurosurg Anesthesiol 8:208-215, 1996

34. Oldfield EH, Muraszko K, Shawker TH, et al: Pathophysiology of syringomyelia associated with Chiari I malformation of the cerebellar tonsils. Implications for diagnosis and treatment. J Neurosurg 80:3-15, 1994

35. Pang D: Sacral agenesis and caudal spinal cord malformations. Neurosurgery 32:775-779, 1993

36. Park TS, Cail WS, Broaddus WC, et al: Lumboperitoneal shunt combined with myelotomy for treatment of syringohydromyelia. J Neurosurg 70:721-727, 1989

37. Schlesinger AE, Naidich TP, Quencer RM: Concurrent hydromyelia and diastematomyelia. AJNR 7:473-477, 1986

38. Schneider SJ, Rosenthal AD, Greenberg BM, et al: A preliminary report on the use of laser-Doppler flowmetry during tethered spinal cord release. Neurosurgery 32:214-218, 1993

39. Sigal R, Denys A, Halimi P, Shapeero L, et al: Ventriculus terminalis of the conus medullaris: MR imaging in four patients with congenital dilatation. AJNR 12:733-737, 1991

40. Sgouros S, Williams B: A critical appraisal of drainage in syringomyelia. J Neurosurg 82:1-10, 1995

41. Taviere V, Brunelle F, Baraton J, et al: MRI study of lumbosacral lipoma in children. Pediatr Radiol 19:316-320, 1989

42. Tripathi RP, Sharma A, Jena A, et al: Magnetic resonance imaging in occult spinal dysraphism. Australas Radiol 36:8-14, 1992

43. van Hall MH, Beuls EA, Wilmink JT, et al: Magnetic resonance imaging of progressive hydrosyringomelia in two patients with meningomyelocele. Neuropediatrics 23:276-280, 1992

44. Williams B: Pathogenesis of syringomyelia, in Batzdorf U (ed): Syringomyelia. Current Concepts in Diagnosis and Treatment. Baltimore: Williams \& Wilkins, 1991, pp 59-90

45. Wisoff JH, Epstein F: Management of hydromyelia. Neurosurgery 25:562-571, 1989

46. Yamada S (ed): Tethered Cord Syndrome. Park Ridge, IL: American Association of Neurological Surgeons, 1996

Manuscript received January 31, 2000.

Accepted in final form February 14, 2000.

Address reprint requests to: Faruk Unal, M.D., Department of Neurosurgery, Istanbul Faculty of Medicine, Istanbul University, 34020 Topkapi, Istanbul, Turkey. email: funal@istanbul.edu.tr. 